Año LII urtea

N. ${ }^{\circ}$ 94. zk.

2020

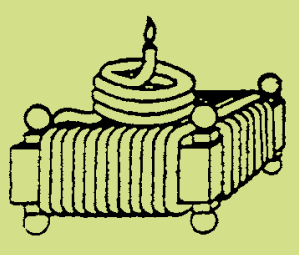

\section{CUADERNOS de Etnología y Etnografía de Navarra}

SEPARATA

\title{
Reseña.
}

La Bizkaia de Navarra.

Memorias de un valle

en silencio

Manuel Navallas Juan 


\section{Sumario / Aurkibidea}

\section{Cuadernos de Etnología y Etnografía de Navarra}

Año LII urtea - N. ${ }^{\circ}$ 94. zk. - 2020

\section{ARTÍCULOS/ARTIKULUAK}

Etxe izen zizelkatuak. Ageriko idazkunak etxeetan eta hilobietan

Koldo Colomo Castro

Recardera, oficio de mujer

Ricardo Gurbindo Gil

Aralar mugarriturik (1523-1857)

Jose Luis Erdozia Mauleon

El lecayo, una soka-dantza del siglo XVI

Ricardo Urrizola Hualde

El recuerdo público de una muerte política: historiografía periodística y etnografía de la ritualidad pública (José Luis Cano Pérez, 1949-1977)

Kepa Fernández de Larrinoa, Karlos Irujo Asurmendi, Santiago Martínez Magdalena, Txuri Ollo Gorriti, Cristina Saura Blanco

El Camino de Santiago en Navarra en 1971 a la luz de un informe para su mejora elaborado por la Dirección de Turismo, Bibliotecas y Cultura Popular Fernando Vega López

Reformulación del discurso significativo sociocultural en el entramado fortificado de la Línea P (Valle de Roncal-Navarra) 


\section{Sumario / Aurkibidea}

NOTICIAS/BERRIAK

Joxe Ulibarrena y su pasión por la Etnografía

Elur Ulibarrena Herce

Normas para la presentación de originales / Idazlanak aurkezteko arauak / 


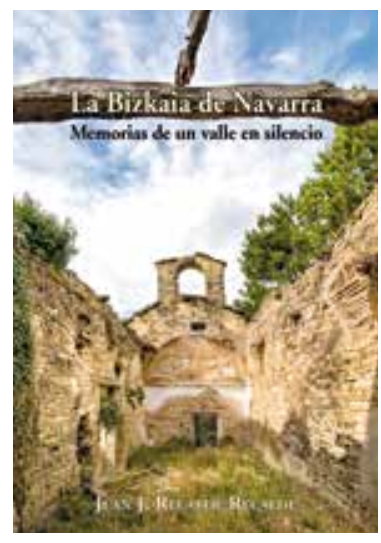

La Bizkaia de Navarra. Memorias de un valle en silencio

RECALDE RECALDE, Juan Jesús

Pamplona: Lamiñarra, 2020, 544 pp.

ISBN: 978-84-09-22823-2

DOI: https://doi.org/10.35462/CEEN94.10

Hablar de la Bizkaia de Navarra supone abrir un cofre del tesoro. La salida de sus pobladores a mediados del siglo XX estratificó los pueblos y las formas de vida y es ahí donde Juan Jesús Recalde, en el año 2017, se dio cuenta de la necesidad de dar voz a este valle que gritaba en silencio la esperanza de recuperar su memoria, que años atrás le habían quitado.

Fruto de su vida en Solchaga, de su conexión con la Valdorba y su ascendencia vizcaína, decidió embarcarse en esta laboriosa tarea que a continuación os presento, no sin antes mencionar el recorrido de investigación histórica que ha llevado a Juan a publicar obras como Esparza, apuntes de genealogía, historia y etnografía. Asimismo, destacar su participación en diversos artículos de investigación y su aporte a los grupos de investigación etnográfica Etniker Euskal Herria. Ese aprecio y puesta en valor de la memoria inmaterial, como son los testimonios orales, aportan una riqueza y un significado de exclusividad al libro que ya por ello debiera despertar la atención del lector que recala en los colores de su portada.

A modo de resumen, el libro cuenta con un total de 544 páginas enmarcadas en dos grandes bloques: uno de contenido histórico en el que se realiza un recorrido por cada uno de los pueblos y otro etnográfico, dividido en temáticas que van desde la vida en el hogar, hasta la religión o la escuela y es aquí donde radica el valor investigador del autor. Además, el libro dispone de un rico, amplio y variado anexo en el que encontramos materiales que van desde fotografías de los pueblos todavía habitados a fotografías actuales, poesía y jotas de ronda. Personalmente he de reconocer que la valía del contenido del anexo es muy considerable, ya que a veces se tiende en obras de investigación a fijar la atención al contenido y se dejan de lado los materiales anexos, y en este caso si queremos una percepción completa de lo que fue la vida en el valle de La Bizkaia, deberemos recurrir a ellos. De especial mención en el contenido del dicho anexo es la labor de reconstrucción topográfica que junto a las personas aún descendientes del valle ha realizado el autor.

No es extraño que la parte histórica suscite interés a aquellos a los que nos apasiona la misma. Sin embargo, esta obra permite conectar también con el lector aficionado a la historia, con el que mantiene vínculo de conexión con el territorio, así como con aquel que desconoce el valle, quien saldrá satisfecho de la riqueza de contenido histórico que la primera parte del libro recoge. De esta forma, se registra desde la documentación de los primeros indicios de vida datados en la Edad del Bronce hasta un repaso por su pasado nobiliar con los palacios «cabo de armería» en Usumbelz, cuyo escudo todavía se conserva, el análisis de la familia Azpilicueta de Sada, la presentación del palacio de 
Soca y del palacio de Loya, donde se hace mención de la «losa sepulcral», una de las joyas del museo dedicado a la Bizkaia. Encontramos también información relativa a la naturaleza de los pobladores de esas tierras, aspecto que deberemos interiorizar para entender la simplicidad de la vida de sus gentes y diversos datos sobre la explotación de hierbas y aguas, la construcción de neveras de almacenaje natural y diversos pleitos que hoy quedan reflejados y el autor ha ido reconstruyendo y significando a través de horas y horas de búsqueda en archivos. Para aquellos que presentan un perfil más investigador, el autor ha incluido tablas de datos acompañadas de su respectivo comentario.

En los compases finales de la parte histórica se presentan dos líneas de investigación que pueden dar pie a futuros debates: Usaregui y Eyzco, ¿qué sabemos de ellos?

En la parte etnográfica, el autor recoge uno de los aspectos que mayor valor le aportan a la obra: la reconstrucción de la vida en el valle a través de la memoria de sus descendientes, que vale la pena mencionar por lo efímero de la misma y que por ello le otorgan una cualidad de exclusividad. Es a través de sus páginas cuando accedemos a conocer con detalle temas como la medicina popular, el trabajo en el campo y con el ganado o las fiestas populares, contenidos y recuerdos que nos acercan a la vida de antaño. Encontrará el lector en esta segunda parte un espacio dedicado al vocabulario utilizado por los habitantes, muestra de la peculiaridad de sus gentes. En definitiva, conocimientos de una zona aislada que ponen en valor la labor de microhistoria realizada.

A modo de conclusión señalar el enorme esfuerzo realizado por Juan Jesús Recalde, las horas dedicadas a la investigación y redacción de una temática que, poco a poco, va perdiendo presencia en el panorama divulgativo pero que juega un papel trascendental para valorar el entorno que nos rodea y comprender las sociedades que nos han precedido.

Manuel Navallas Juan

Historiador y gestor cultural del

Museo Etnográfico «La Vizcaya» (Ayesa, Navarra) 